Article

\title{
Design and Implementation of Probabilistic Transient Stability Approach to Assess the High Penetration of Renewable Energy in Korea
}

\author{
Young-Been Cho ${ }^{1}$, Yun-Sung Cho ${ }^{1, * \mathbb{D}}$, Jae-Gul Lee ${ }^{2}$ and Seung-Chan $\mathrm{Oh}^{2}$ \\ 1 School of Electronic and Electrical Engineering, Daegu Catholic University, Gyeongbuk 38430, Korea; \\ gust741719@gmail.com \\ 2 Power System Analysis, Korea Electric Power Research Institute, Deajeon 34056, Korea; \\ jaegul.lee@kepco.co.kr (J.-G.L.); seungchan.oh@kepco.co.kr (S.-C.O.) \\ * Correspondence: philos@cu.ac.kr; Tel./Fax: +82-53-850-2767
}

check for updates

Citation: Cho, Y.-B.; Cho, Y.-S.; Lee, J.-G.; Oh, S.-C. Design and Implementation of Probabilistic Transient Stability Approach to Assess the High Penetration of Renewable Energy in Korea. Sustainability 2021, 13, 4205 https://doi.org/10.3390/ su13084205

Academic Editor: Ocktaeck Lim

Received: 7 March 2021

Accepted: 7 April 2021

Published: 9 April 2021

Publisher's Note: MDPI stays neutral with regard to jurisdictional claims in published maps and institutional affiliations.

Copyright: (c) 2021 by the authors. Licensee MDPI, Basel, Switzerland. This article is an open access article distributed under the terms and conditions of the Creative Commons Attribution (CC BY) license (https:/ / creativecommons.org/licenses/by/ $4.0 /)$.

\begin{abstract}
Recently, because of the many environmental problems worldwide, Korea is moving to increase its renewable energy output due to the Renewable 3020 Policy. Renewable energy output can change depending on environmental factors. It is for this reason that institutions should consider the instability of renewables when linked to the electric system. This paper describes the methodology of renewable energy capacity calculation based on probabilistic transient stability assessment. Probabilistic transient stability assessment consists of four algorithms: first, to create probabilistic scenarios based on the effective capacity history of renewable energy; second, to evaluate probabilistic transient stability based on transient stability index, interpolation-based transient stability index estimation, reduction-based transient stability index calculation, etc.; third, to implement multiple scenarios to calculate renewable energy capacity using probabilistic evaluation index; and finally, to create a probabilistic transient stability assessment simulator based on Python. This paper calculated renewable energy capacity based on large-scale power system to validate consistency of the proposed paper.
\end{abstract}

Keywords: renewable energy; probabilistic transient stability; transient stability index; cumulative distribution functions (CDF); automatic simulation based on Python

\section{Introduction}

Because of climate change and worsening environmental problems around the world, countries are urged by the international community to reduce their carbon emissions under the UN Climate Change Conference Paris 2015. Reducing the national carbon footprint means abolishing coal and thermal power plants, which were primarily responsible for carbon emissions, and using renewable energy resources [1]. As shown in Figure 1, Korea aims to produce $20 \%$ of its total energy output with renewable energy generation by 2030 , which is around 63.8 gigawatts (GW) (Photovoltaics (PV): 57\%; Wind: 28\%; Others: 15\%) according to the Renewable 3020 Policy [2].

Korea recently achieved an 8.6\% renewable energy output in the third quarter of 2019. An increase in renewable energy production has an inevitable effect on the electric system. Producing renewable energy requires the assessment of variables that are not typically considered in conventional types of energy production. These variables depend on regional inputs and climates, so it is crucial to analyze these characteristics and their impact on the system.

Recently, on the largest island of Korea, Jeju Island, on 13 April 2020, at 3:58 p.m., the load was $617 \mathrm{MW}$, the renewable generation such as wind power and solar power recorded $384 \mathrm{MW}$, and the renewable Effective capacity was $62.3 \%$. However, the curtailment in Jeju last year increased by $67.4 \%$ compared to the previous year to 77 . Such curtailment led to a power limitation of 2.2 million $\mathrm{kWh}$ (worth 4 billion), which was directly linked 
to losses for wind power generators. This means that even if new and renewable energy is actively carried out, there is a lack of foundation for efficient use of it. It is known that the Jeju region is implementing curtailment for wind power generation every year as the acceptance of renewable energy has reached its limit. The problem is that curtailment increases rapidly as the years go by: from 3 in 2015 to 6 in 2016, 14 in 2017, 15 in 2018, and 46 in 2019 [3]. Therefore, it is necessary to probably predict changes in the generation of renewable energy in the pre-planning stage for these losses and problems to prevent problems caused by the amount of generation of renewable energy.

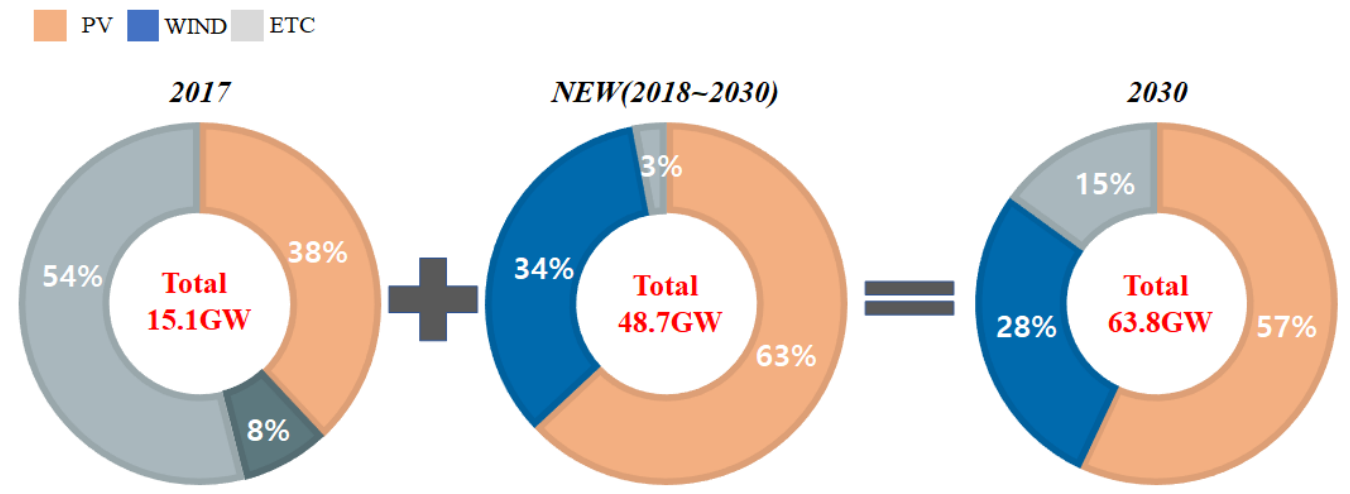

Figure 1. Status of the renewable energy 3020 implementation plan.

Power system stability assessment for large-scale power system complexes has been conducted in a deterministic method. Deterministic method can analyze properties of power systems through scenario creation, load flow calculation, and N-1 contingency analysis. However, when the volatility increases with alignment of a power system with renewable energy, this limits application of deterministic method. To supplement limitations of deterministic method, the probabilistic stability assessment method has been used, where scenarios extending to $8760 \mathrm{~h}$ are created to assess stability. Table 1 shows characteristics of the deterministic method and the probabilistic method to estimate renewable energy capacity limits.

Table 1. Characteristic of Deterministic method and Probabilistic method.

\begin{tabular}{|c|c|c|}
\hline & Characteristic & Required Input Data \\
\hline Deterministic method & 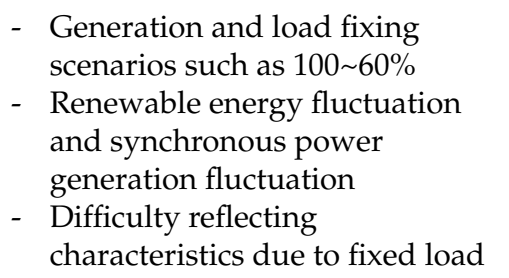 & $\begin{array}{l}\text { - } 100 \sim 60 \% \text { scenario } \\
\text { - } \text { Regeneration e facility } \\
\text { capacity } \\
\text { - Synchronous Generator } \\
\text { Merit Order }\end{array}$ \\
\hline Probabilistic method & $\begin{array}{ll}\text { - } & 8760 \mathrm{~h} \text { reflected } \\
\text { - } & \text { Generation (synchronous power } \\
\text { generation, renewable e) } \\
\text { fluctuations, load fluctuations } \\
\text { - } \quad \text { Difficulty securing convergence } \\
\text { due to power generation and } \\
\text { load fluctuations }\end{array}$ & $\begin{array}{l}\text { - Development/demand } \\
\text { history database (DB) } \\
\text { required for several years } \\
\text { - } \text { Renewable e facility capacity } \\
\text { - Synchronous Generator } \\
\text { Merit Order }\end{array}$ \\
\hline
\end{tabular}

Recently, a number of studies have been conducted on power system planning and assessment using probabilistic stability assessment. National Grid ESO(NGESO) used the probabilistic stability assessment procedure to create its scenarios for expanding the renewable energy generation and plan to reinforce its transmission and transformation 
facilities [4]: in one study, through deterministic transient stability evaluation using CCT (Critical Clearing Time), etc. (the transient stability state of the power grid; calculate the stability margin of several generators). Through this simulation, it is expressed as PDFs (Probability density functions), which is a probabilistic index, and examined as an enemy [5]. Another paper introduces the Monte Carlo simulation-based methods to create a scenario with multiple load models. After that, the transient stability assessment by a probabilistic approach used the normal and cumulative distributions using Transient Stability Index (TSI) and generator damping(s) [6]. Figure 2 shows the flow chart of the plan to reinforce their transmission and transformation facilities based on the probabilistic stability assessment procedure. As shown in Figure 2, both the deterministic and probabilistic methods establish the reinforcement plan by calculation based on repeated load flow calculation. However, the probabilistic method establishes the reinforcement plan by applying the probabilistic method to estimate generation and load configuration, flow capacity of lines connecting regions, etc., based on the history data. A precise plan to reinforce transmission and transformation facilities requires a probabilistic transient stability assessment.

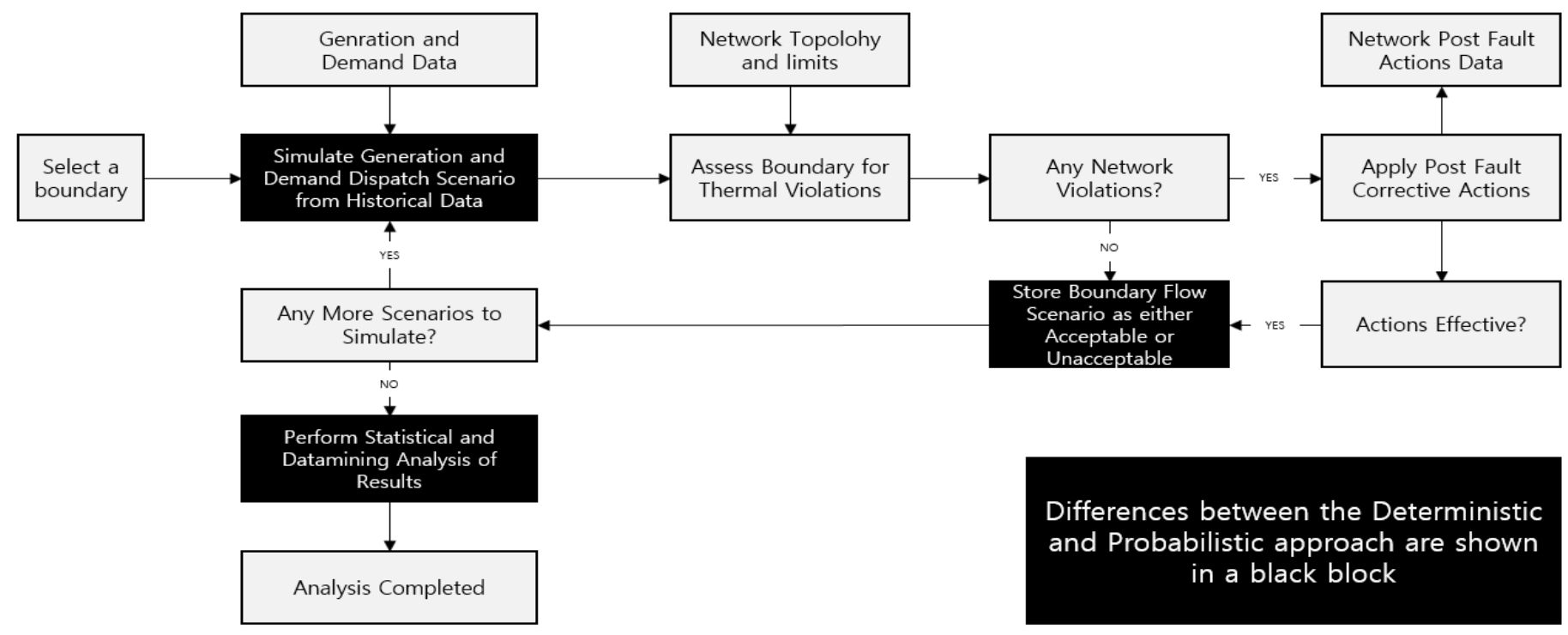

Figure 2. Power system stability and renewable energy acceptance analysis of probabilistic method [4].

Many studies are being conducted based on probabilistic stability based on algae calculation and assumed contingency fault, the expansion of new and renewable energy [7-12]. However, the probabilistic stability analysis based on the power flow calculation has a disadvantage in that it cannot reflect the transient characteristics. In particular, there are unstable areas in terms of transient stability in Korea, and generator output decreasing and Special Protection System (SPS) are installed and operated to solve this problem. In this paper, a probabilistic transient stability plan that reflects the dynamic characteristics of generators and new renewable energy is proposed to compensate for the shortcomings of the probabilistic stability based on power flow calculation.

This paper introduces algorithms of the probabilistic transient stability assessment considering volatility and uncertainty of renewable energy. First, probabilistic scenarios were created based on the history of effective capacity and generation for $8760 \mathrm{~h}$ of renewable energy. A sum of 8760 scenarios are created by applying the generation quantity from the historical data based on the input data of the maximum generation scenario. Second, a probabilistic transient stability assessment was conducted using transient stability index, interpolation-based transient stability index estimation, reduction-based transient stability index, etc. To reduce calculation time, which is a disadvantage of the probabilistic transient stability assessment, interpolation and reduction algorithms were applied to the transient stability assessment. Finally, a probabilistic transient stability assessment simulator was 
created based on the scenario creation, transient stability assessment algorithms, and probabilistic assessment. This paper created 5 scenarios to validate consistency of the proposed paper.

\section{The Proposed Flowchart for Probabilistic Transient Stability Assessment}

\subsection{Overall Flowchart}

Figure 3 shows the procedure of the proposed probabilistic transient stability assessment. The probabilistic transient stability assessment consists of five modules:

- Scenario creation module: to create 8760-h scenarios or scenarios for different increase/decrease ratios of renewable energy

- Transient stability assessment module: stability assessment based on transient stability index, stability assessment based on interpolation and reduction

- Wind turbine gust modelling module: Wind turbine gust modelling using a dynamic model for renewable energy

- Probabilistic assessment module: Probabilistic analysis and output in PDF and cumulative distribution functions (CDF) based on the results of the transient stability assessment

- Output module: Transient stability assessment results (text, charts, etc.) output, log output, etc.
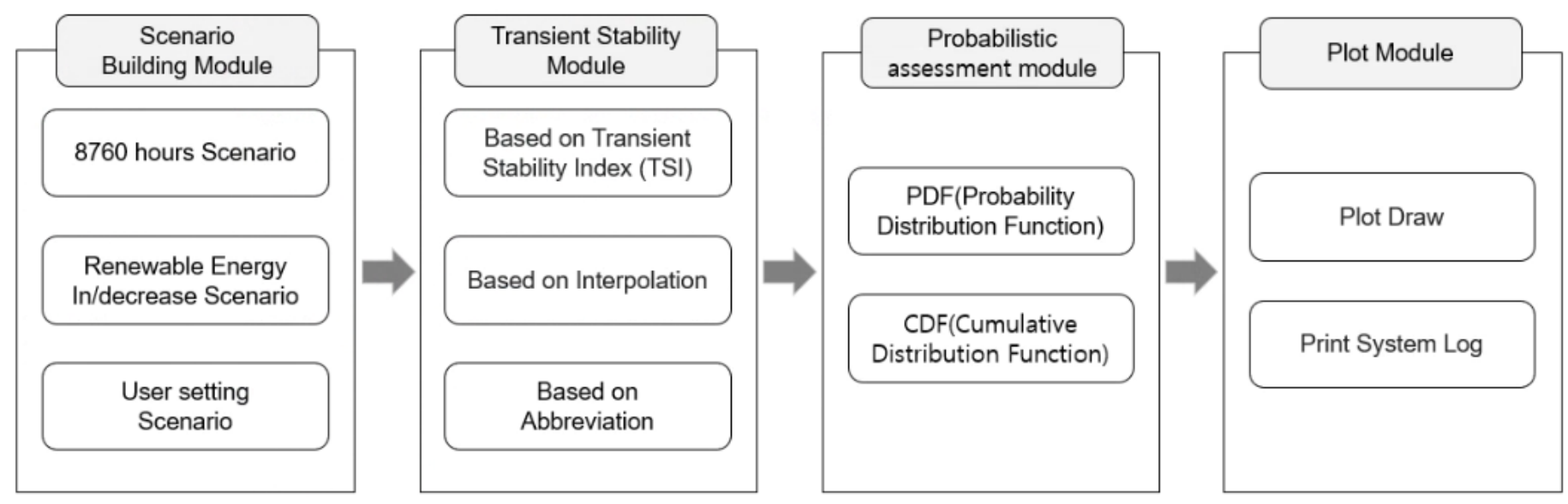

Figure 3. Flowchart of simulation module of probabilistic method.

\subsection{Scenario Creation}

For the probabilistic transient stability assessment, scenarios were created based on the following data:

- Input data: Basecase data (Power System Simulation for Engineering (PSS/E) data format), information on renewable energy link (interconnected bus, type and capacity of the renewable energy)

- $\quad$ Scenario Creation Process

(1) Renewable energy is modelled into the basecase. As shown in Figure 4a, it is modelled using a simple renewable energy topology. This study simplified the modelling method and used connecting lines and transformers for modelling. Additionally, generators with step-up transformers are used to reduce the database size. As shown in Figure $4 b$, it is modelled using a dynamic model of renewable energy. Solar and wind power models are applied using the Western Electricity Coordinating Council (WECC) second generation model [13].

(2) Renewable energy generation quantity is adjusted based on the effective capacity data of renewable energy. As shown in Figure 5, the hourly generation of solar and wind power in Korea in 2019 is not constant and is distributed in various ways. Based on this, the amount of renewable energy output is 
adjusted in several stages. In this paper, the modeled effective capacity of renewable energy composed of $1 \%$ to $95 \%$.

(3) When the scenario is generated for the static analysis, the renewable energy power system was connected, leading to an increase in the amount of renewable energy generation, which causes errors in supply and demand, thereby enlarging the mismatch in the power system. To rebalance the supply and demand, either the existing generator should be suspended via dispatch, or the amount of power generation must be reduced. Thus, Generators are dispatched based on the merit order of the generators.

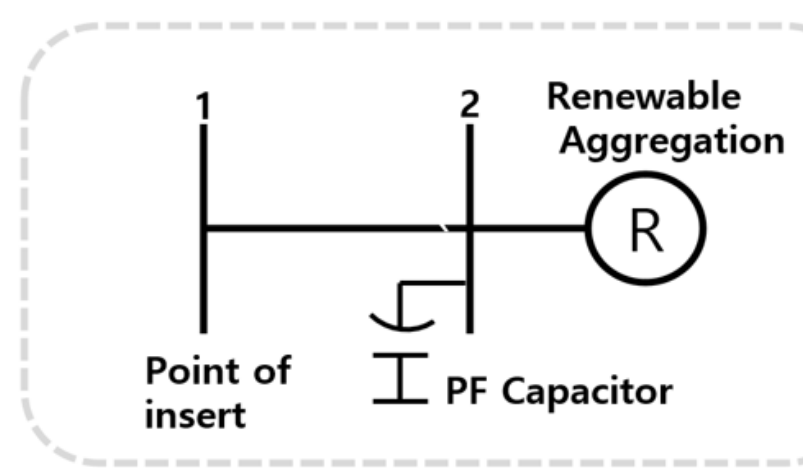

(a)

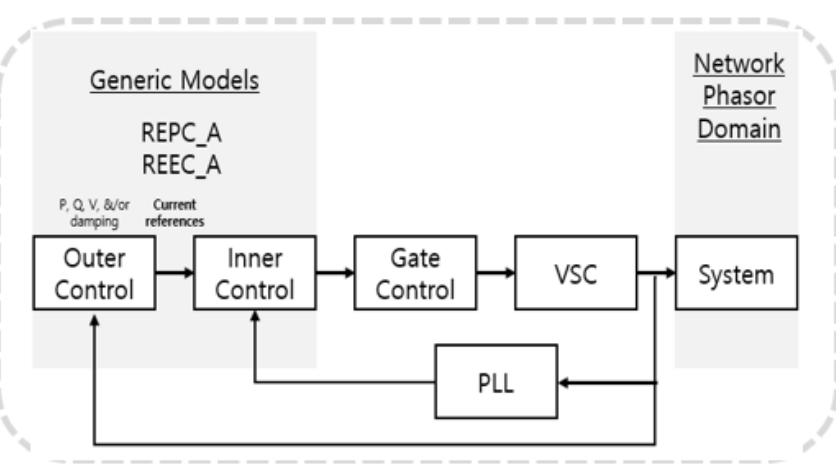

(b)

Figure 4. (a) The proposed power flow model of renewable energy. (b) Structure of generic model in WECC 2nd [12].

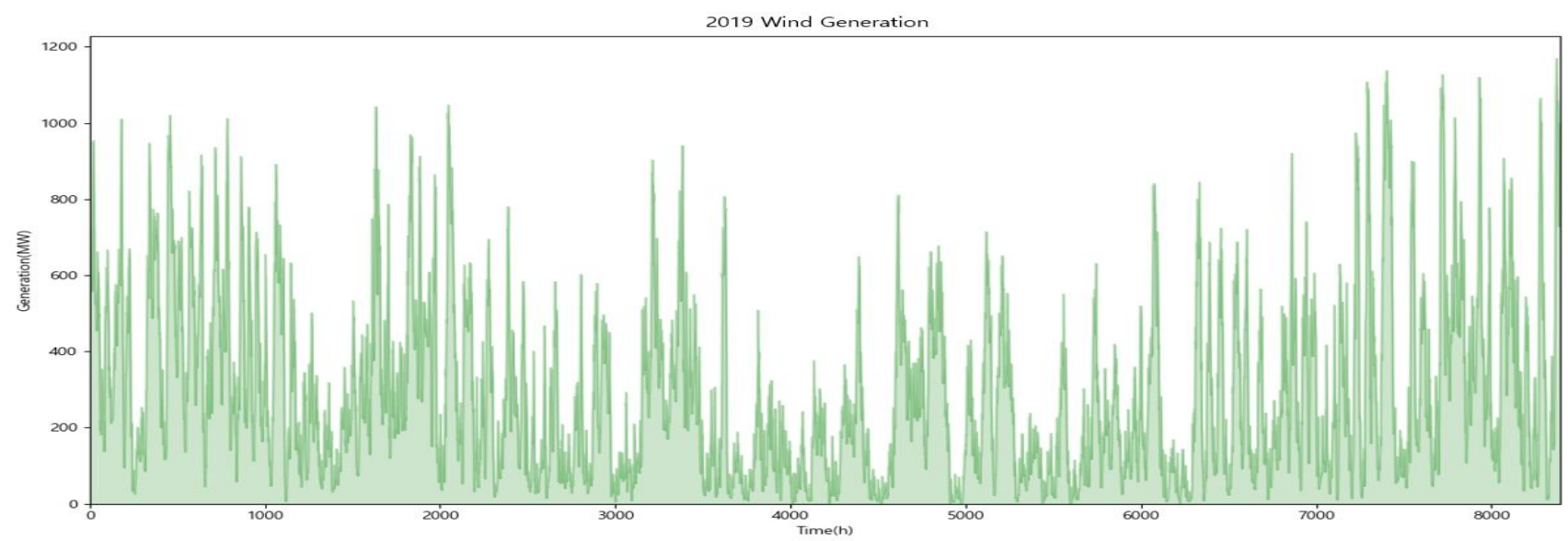

(a)

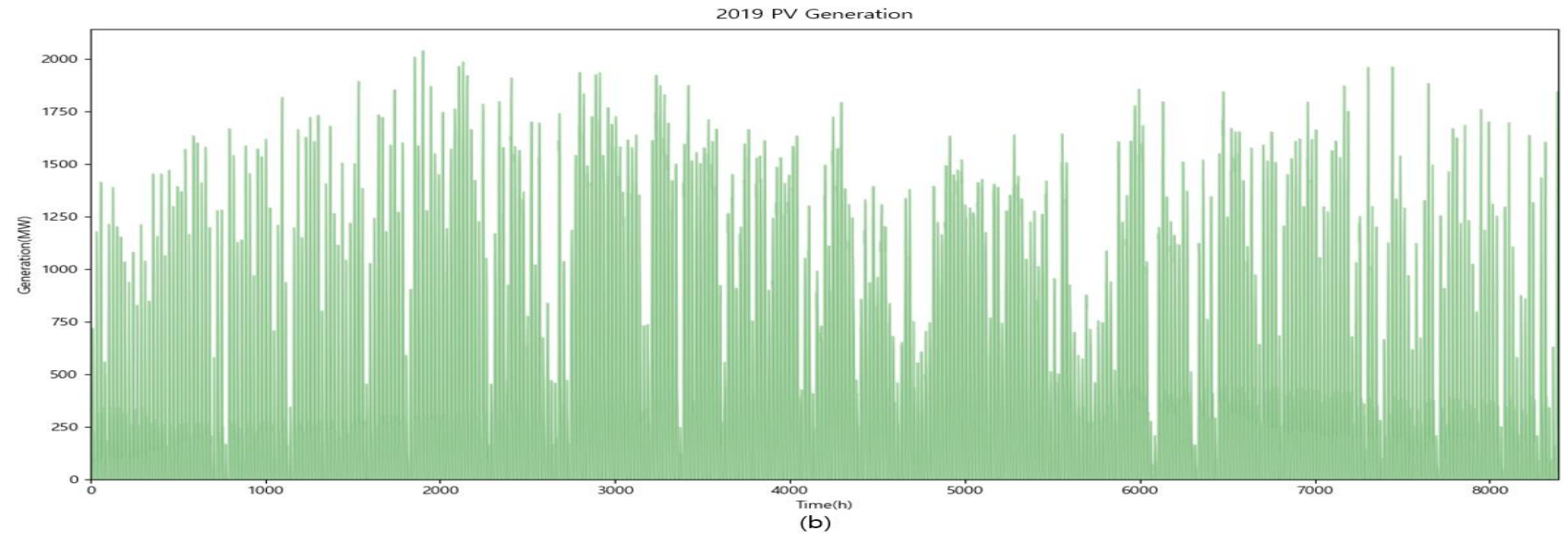

Figure 5. (a) Generation of 2019 Wind generation in Korea. (b) 2019 Generation of 2019 Wind generation in Korea [1,2]. 


\subsection{Transient Stability Assessment}

\subsubsection{Transient Stability Assessment Based on Transient Stability Index (TSI)}

This paper evaluated stability and instability of a power grid using phase angles of the generators for the probabilistic transient stability assessment. As shown in Formula (1), the stability index was established using phase angles of the generators [14].

$$
\mathrm{TSI}=100 \times \frac{360-\sigma_{\mathrm{MAX}}}{360+\sigma_{\mathrm{MAX}}}
$$

where $\sigma_{\text {MAX }}$ is the maximum rotor angle deviation. For systems with a stable condition, the TSI will be greater than the threshold value. The thresholds may be set according to characteristics of the power grids of each country. This paper declared instability for 35 or lower, considering characteristics of the power grids in Korea. As shown in Figure 6, TSI of 35 or lower generally shows instability. This indicator allows one to quickly identify the probability of falling below a given TSI level. Although the probabilistic transient stability assessment is a precise stability assessment methodology, a disadvantage is that it requires a long time for calculation. This study proposed two algorithms to reduce the calculation time of the probabilistic transient stability assessment. First, is the interpolation-based probabilistic transient stability assessment. Second, is the reduction-based probabilistic transient stability assessment.

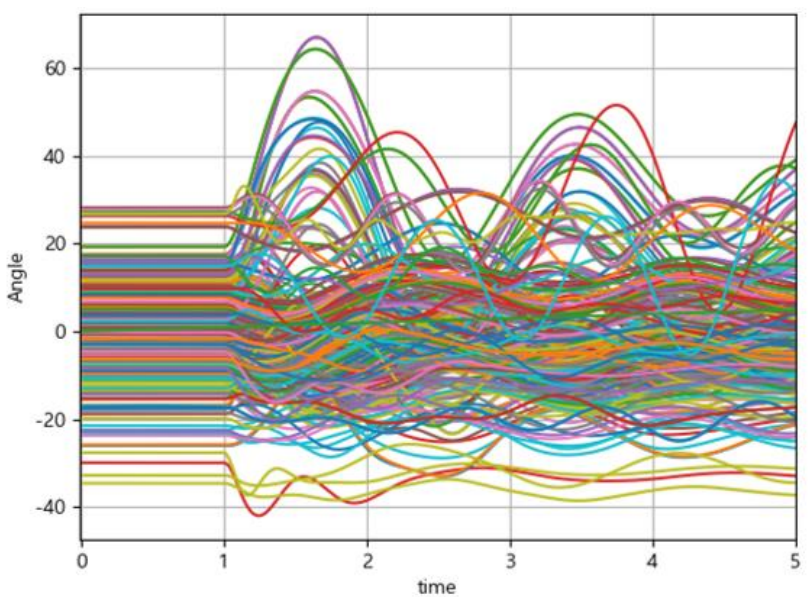

(a)

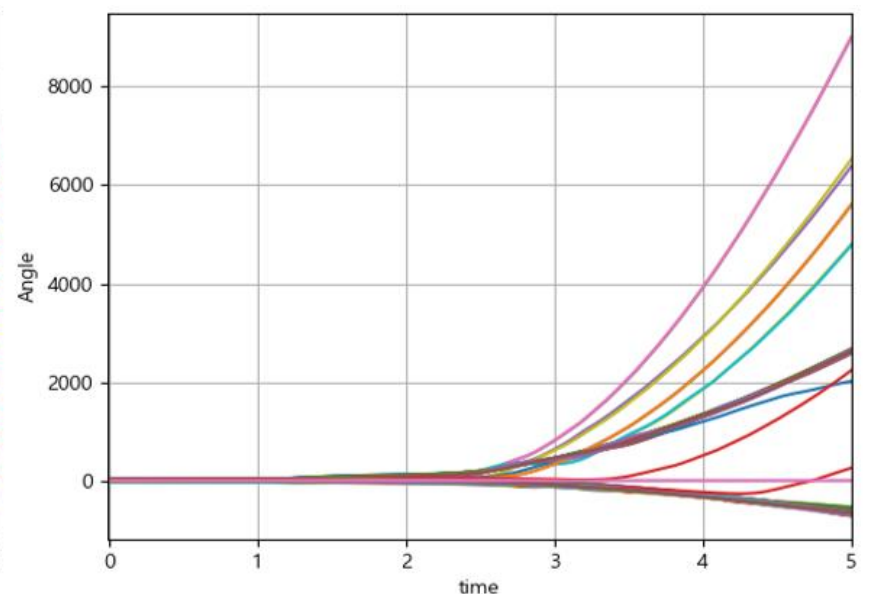

(b)

Figure 6. Stability result according to Transient Stability Index (TSI). (a) TSI 35: Stable state. (b) TSI < 35: Unstable state. Colored line: angle of each generator.

\subsubsection{Interpolation-Based Transient Stability Assessment}

The interpolation-based probabilistic transient stability assessment can calculate capacity of renewable energy by simulating fewer scenarios. As shown in Figure 7, the interpolation method calculates a predicted value by extracting a least squares polynomial fit for a given data. The process of the interpolation-based probabilistic transient stability assessment with Python [15] is as follows:

Step (1) Scenarios are selected for the transient stability assessment. The minimum capacity and average capacity of renewable energy are determined to calculate critical capacity of renewable energy. This study applied the average capacity based on the effective capacity.

Step (2) A total of 10 scenarios are selected with increases/decreases in renewable energy between the minimum and average capacities.

Step (3) For the scenarios selected in Step (2), TSI-based transient stability assessment is conducted.

Step (4) the maximum capacity of renewable energy is calculated based on interpolation. 


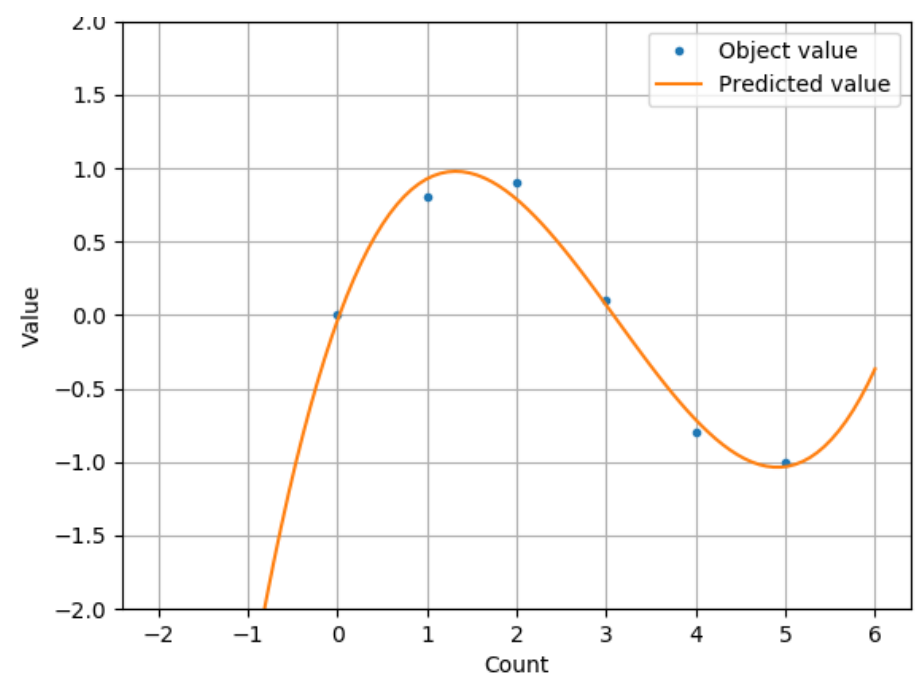

Figure 7. Interpolation using Python.

\subsubsection{Reduction-Based Transient Stability Assessment}

The reduction-based probabilistic transient stability assessment can calculate renewable energy capacity by equalizing large-scale systems as interested systems and simulating the scenarios. The process of the reduction-based probabilistic transient stability assessment is as follows:

Step (1) Interested areas and uninterested areas are selected for the transient stability assessment.

Step (2) For the uninterested areas, generators and buses of $154 \mathrm{kV}$ or higher are maintained and the rest is reduced.

Step (3) For the scenarios in Step (2), TSI-based transient stability assessment is conducted.

Step (4) As shown in Figure 8, calculate the maximum capacity for renewable energy by using the little difference between voltage and phase angle before and after reduction.

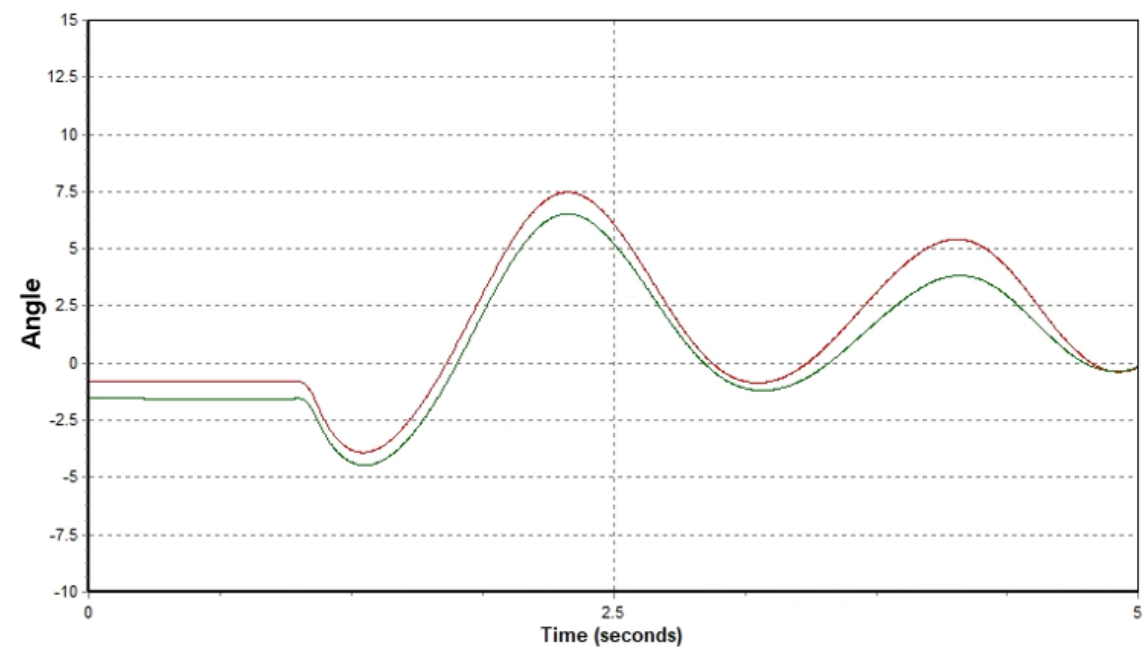

Figure 8. Generator angle before and after Reduction (Red: Before, Green: After).

\subsection{Wind Gust Modeling}

The generic model provided by PSS/E in the dynamic modeling of the generators that make up the renewable energy complex. Generator modeling consists of REGCAU1 [16,17], the electrical and mechanical modeling of REECAU1, and REPCAU1's pitch control as shown in Figure 9. In this paper, the generation of wind changed the value of Model VARS $(\mathrm{L}+3)$ of REPCAU1, which is the pitch control model, to realize the output variation of 
renewable energy. In addition, the proposed method improved the speed of the output fluctuation by changing the control gain value and speed up the fluctuation. We then multiplied the parameter value by the model generator's install capacity to match the actual generation output. Afterward, the test system confirmed that the output changed. Figure 10 shows that the existing Pgen (power generation) value of the test system changed from $66.528 \mathrm{MW}$ to $65.8 \mathrm{MW}$, where the Pgen value was reduced by about $1 \%$ in $1 \mathrm{~s}$.

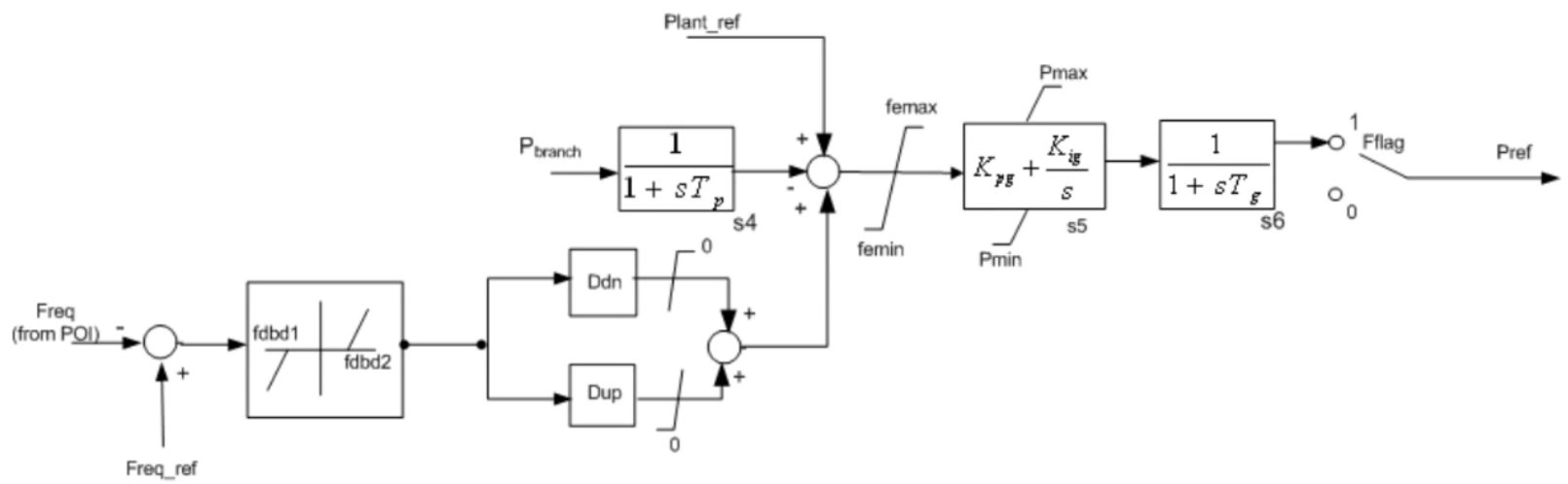

Figure 9. REPCAU1 Model of PSS/E [16,17].

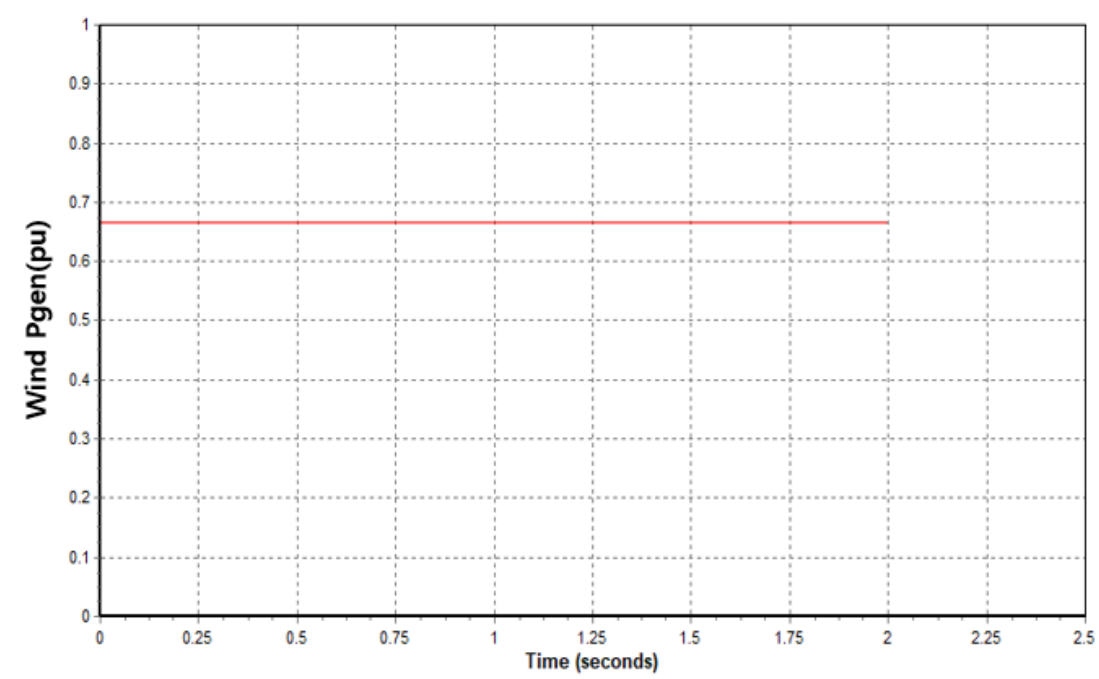

(a) Before variation

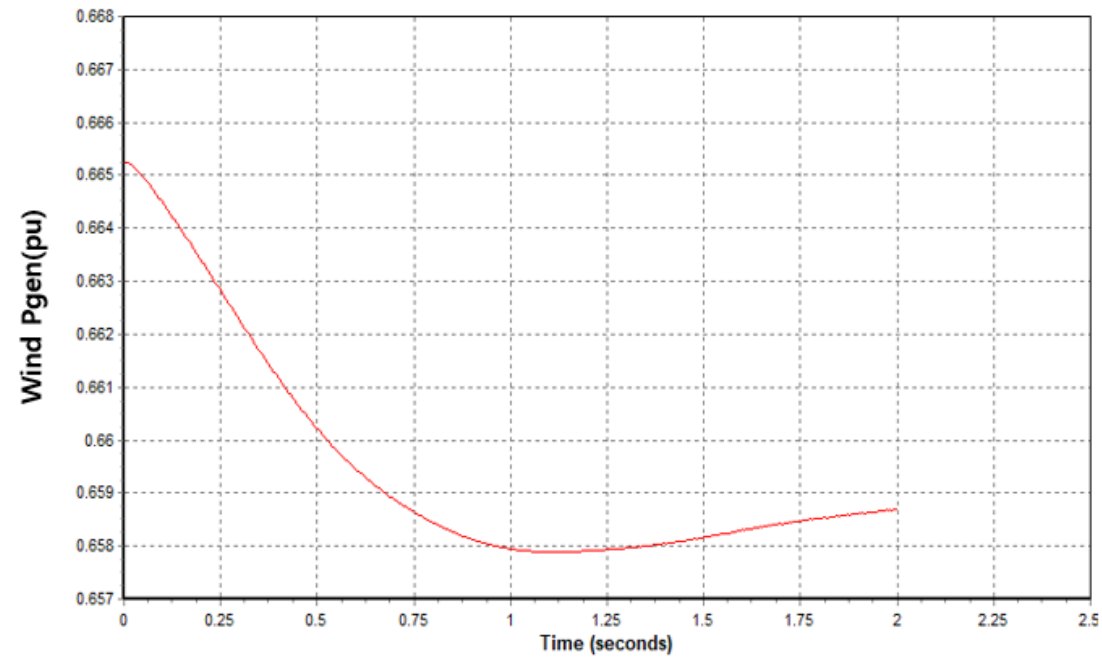

(b) After variation

Figure 10. Compared to variation Wind Pgen. 


\section{Implementation of Probabilistic Transient Stability Assessment Simulator}

\subsection{Overall Flowchart}

This paper created a probabilistic transient stability assessment simulator with the PSS/E transient stability assessment engine and Python. As shown in Figure 11, the simulator was designed by developing a variety of algorithms based on the PSS/e transient stability interpretation engine. As shown in Figure 11, the probabilistic transient stability module is mainly composed of Python and PSS/E engines. Each module is connected by Python, and general steady state and probabilistic review are possible by using the function of PSS/E.

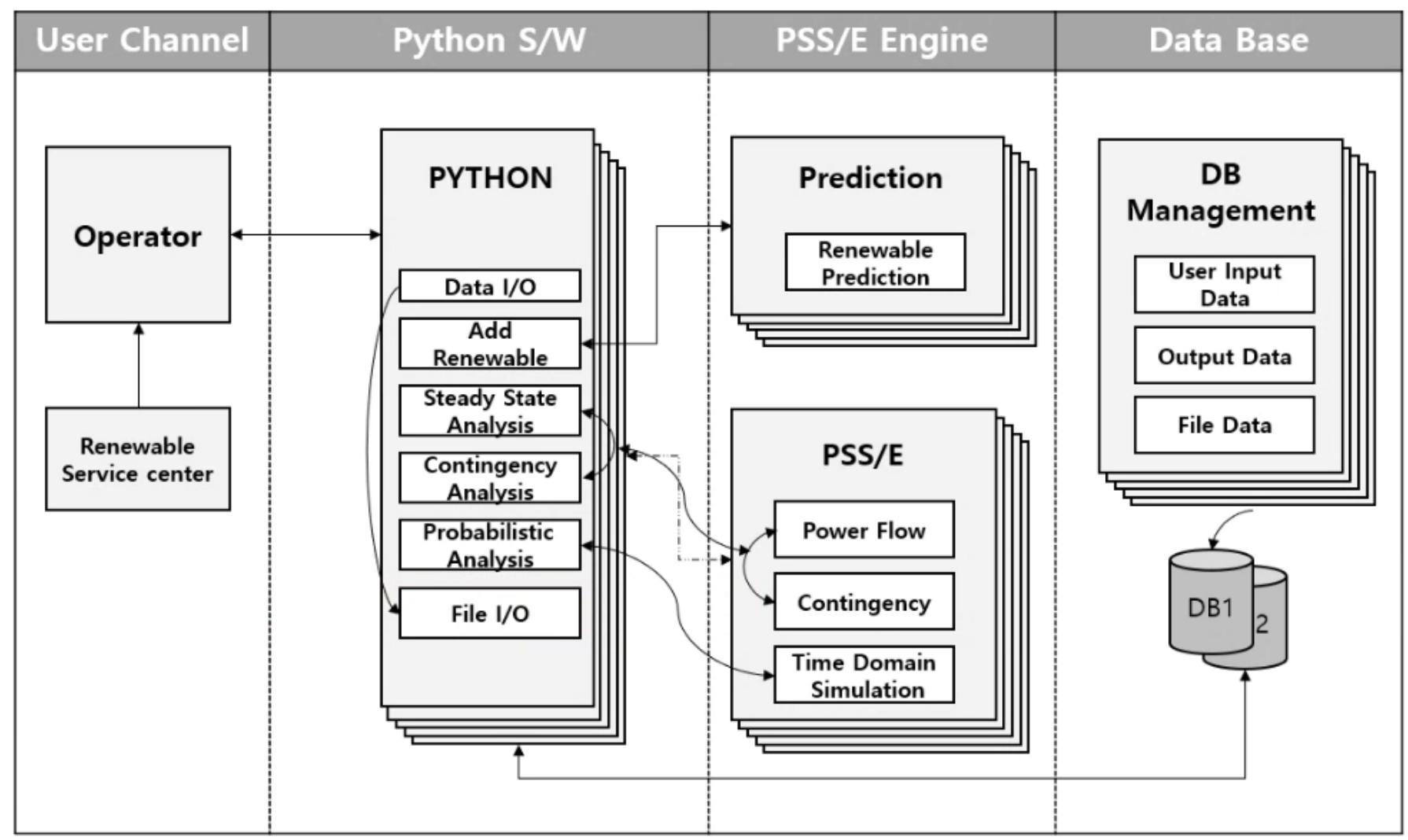

Figure 11. Construction of a probabilistic transient stability simulator using Python.

\subsection{Major Display of Simulator}

It shows the basic display of the stochastic transient stability simulator, as shown in Figure 12. The simulator includes scenario generation, transient stability assessment, and rapid transient stability assessment including system contraction. For user convenience, the settings consist of various parameters. For example, in transient stability evaluation, failure time, simulation time, list of assumed accidents, scenario data, etc., are included. 


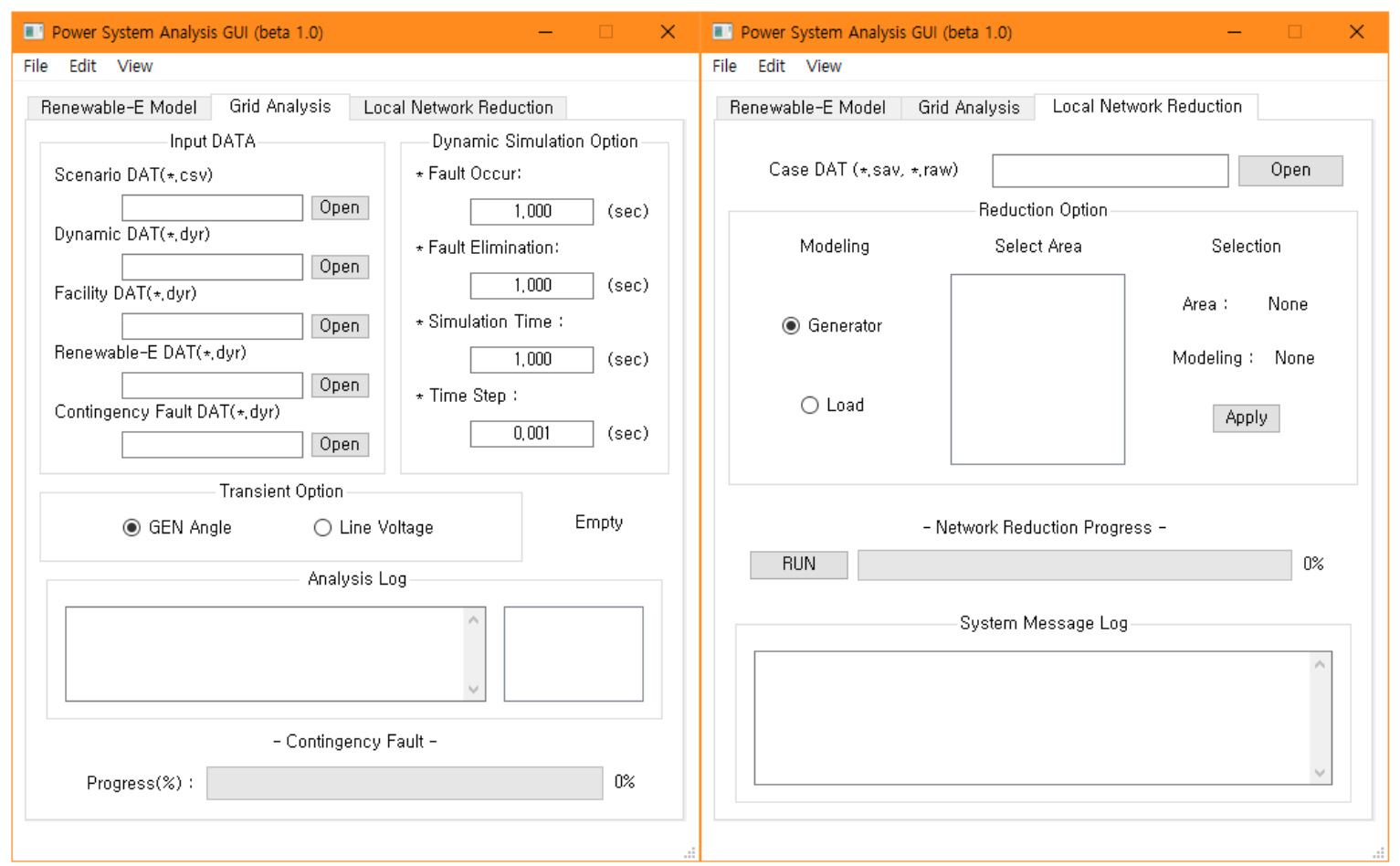

Figure 12. Probabilistic transient stability simulator main functions and User Interface (UI).

\section{Case Study}

In this section, several scenarios were reviewed based on the above-mentioned stochastic transient stability method. The reviewed scenarios are shown in Table 2 below.

Table 2. Probabilistic scenarios.

\begin{tabular}{cl}
\hline No. & \multicolumn{1}{c}{ Description } \\
\hline Scenario A & $\begin{array}{l}665 \text { cases, which is 95 cases with effective capacity of 1 } \\
95 \% \text { in Region A times 7 contingencies }\end{array}$ \\
Scenario B & Simulating the 95 cased in Scenario A with the reduction method \\
Scenario C & Estimating stability of some cases with interpolation method \\
Scenario D & Simulating stability with the volatility of renewable energy using the gust model \\
Scenario E & Comparing calculation time \\
\hline
\end{tabular}

\subsection{Scenario A}

In this scenario, the power system database for the probabilistic transient stability and capacity thresholds in the East area of Korea includes the following:

- $\quad$ The confirmed amount of renewable energy plan for 2034

- $\quad$ Load levels of $100 \%$

- $\quad 1 \%$ increase of power production in the East area (approximately $83 \mathrm{MW}$ )

- $\quad 5.4 \mathrm{GW}$ of power production in other areas, 7 contingencies in the East area

As shown in Tables 3 and 4, 95 scenarios and 7 contingencies were established and analyzed. The solar facilities were set to $4.1 \mathrm{GW}$, and the wind to $4.2 \mathrm{GW}$ in the East area.

Table 3. Index of Case

\begin{tabular}{cccccccccccccc}
\hline Level (\%) & 1 & 2 & 3 & 4 & 5 & 6 & 7 & 8 & $\sim$ & 92 & 93 & 94 & 95 \\
\hline $\begin{array}{c}\text { Renewable } \\
\begin{array}{c}\text { Generation } \\
\text { (MW) }\end{array}\end{array}$ & 83 & 166 & 249 & 332 & 415 & 498 & 581 & 664 & $\sim$ & 7659 & 7742 & 7825 & 7908 \\
\hline
\end{tabular}


Table 4. Index of contingency list.

\begin{tabular}{cccc}
\hline No. & Name & Voltage Level & Active Power (MW) \\
\hline Contingency 1 & SGP-GN & 765 & 2510 \\
Contingency 2 & ST-SHW & 765 & 984 \\
Contingency 3 & ST-GN & 765 & 1674 \\
Contingency 4 & GN-DH & 345 & 120 \\
Contingency 5 & GN-GN\#2 & 345 & 1846 \\
Contingency 6 & SC-DH & 345 & 326 \\
Contingency 7 & SYJ-SJ & 345 & 296 \\
\hline
\end{tabular}

Note: Acronymized names of the regions in Korea are used in column 2.

Figure 13 above shows the probability distribution and cumulative distribution of the 665 cases. The blue areas represent stable areas, and the red areas represent instable areas. According to the CDF diagram, the probability that the value is lower than 35, which is the TSI threshold for instability in the Korean system is $4.81 \%$. Additionally, Figure 13 shows that the TSI index falls below 35 where the effective capacity is $63 \%$, which has approximately $5.3 \mathrm{GW}$ of renewable energy power production in the East area. As shown in Table 5, the time where TSI exceeds is shortened after the $63 \%$. Therefore, the renewable energy capacity in Region A is thought to be approximately $5.3 \mathrm{GW}$. The overall simulation took about $73 \mathrm{~min}$.

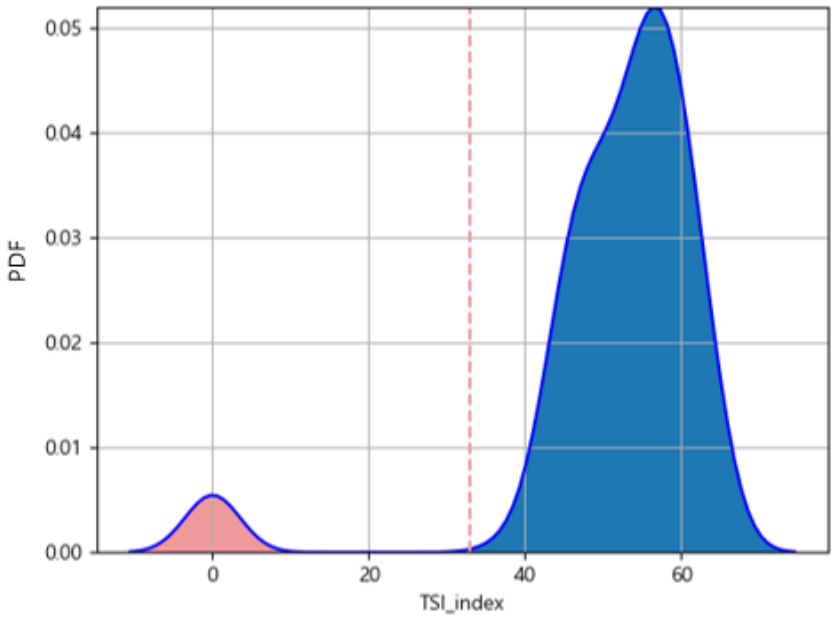

(a)

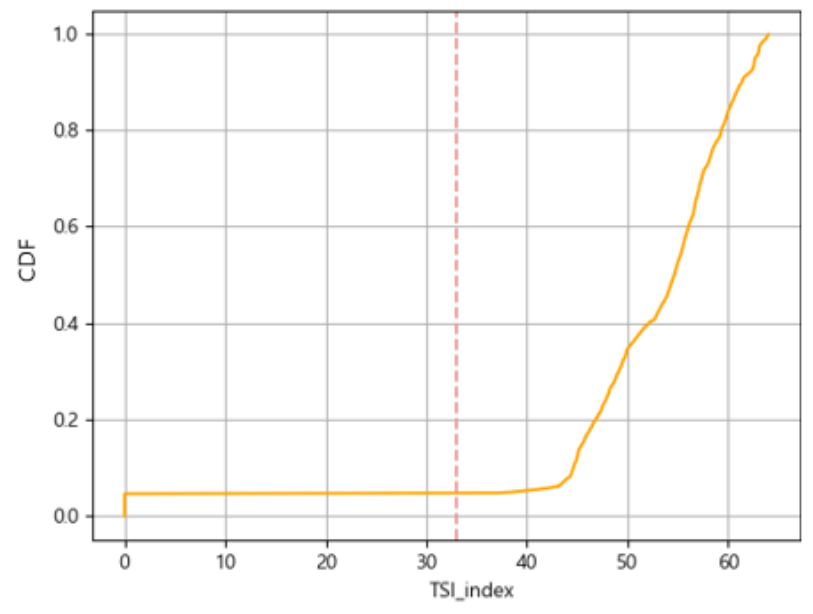

(b)

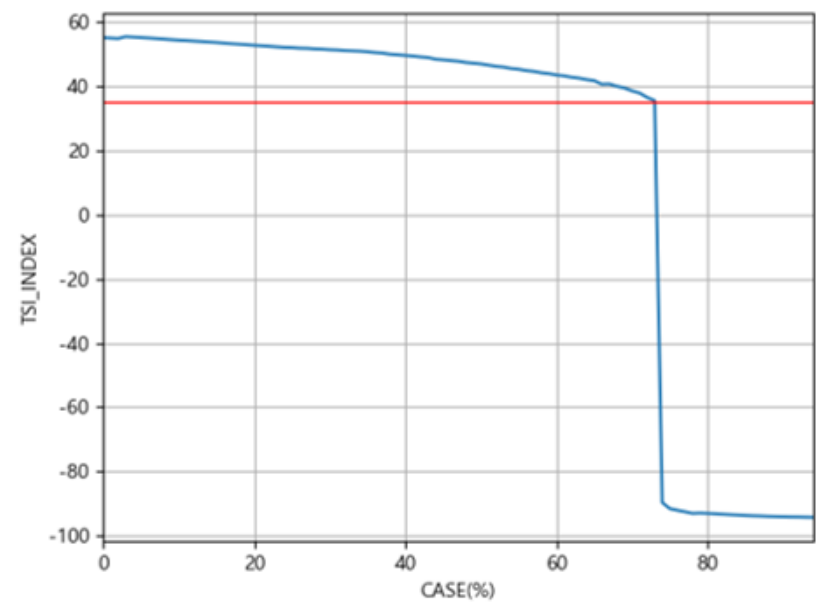

(c)

Figure 13. (a) Probability density functions, (PDF) (b) Cumulative distribution functions (CDF), (c) TSI of case. 
Table 5. Transient Stability Index (TSI) and unstable time of each case.

\begin{tabular}{cccccc}
\hline Scenario No. & TSI & Time & Scenario No & TSI & Time \\
\hline 1 & 54.9751 & Stable & 14 & 52.722 & Stable \\
5 & 54.41605 & Stable & 18 & 51.98562 & Stable \\
& & & & & \\
63 (Unstable) & $-\mathbf{9 8 . 1 7 9 9}$ & 3.351 & 72 & -98.5122 & 2.435983 \\
64 & -98.2984 & 2.951976 & 73 & -98.5222 & 2.415983 \\
& \multicolumn{2}{c}{$\sim$} \\
\hline
\end{tabular}

\subsection{Scenario $B$}

In this scenario, for the 95 cases in Scenario A, except for the East area, which is the interested area, buses of $154 \mathrm{kV}$ or higher were maintained to assess the transient stability through the reduction method. During the reduction, the base generation in the uninterested regions is maintained to identify system characteristics. As shown in Figure 14 , the probability distribution where $3 \%$ error occurs in the probability of TSI index is lower than 35. As shown in the table, the simulation of all the transient stabilities took about $56 \mathrm{~min}$, which is about $17 \mathrm{~min}$ shorter than Scenario A. Overall, the accuracy has some error, but the speed is superior.

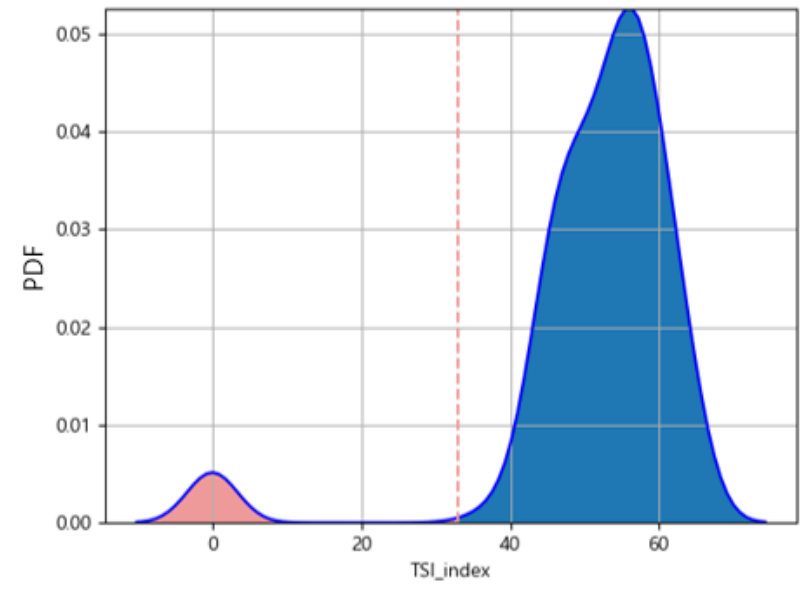

(a) Before reduction PDF

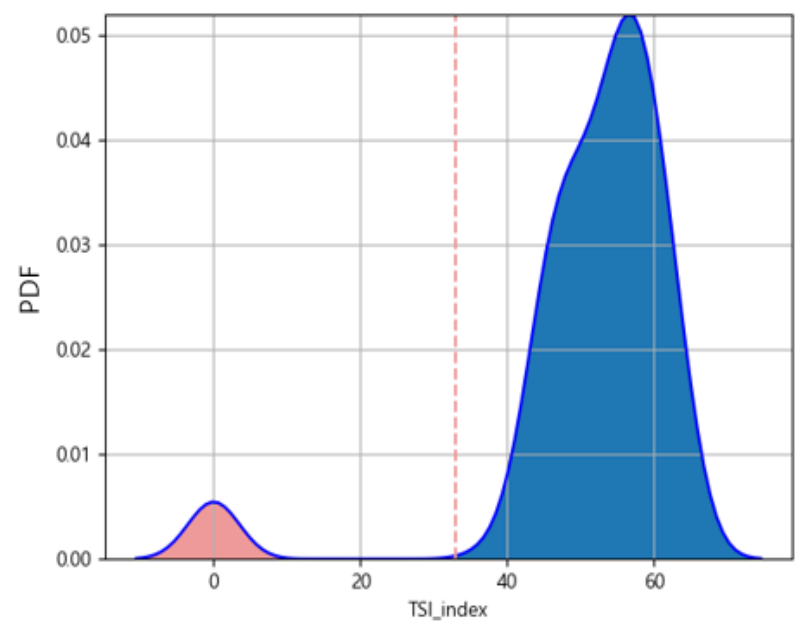

(c) After reduction PDF

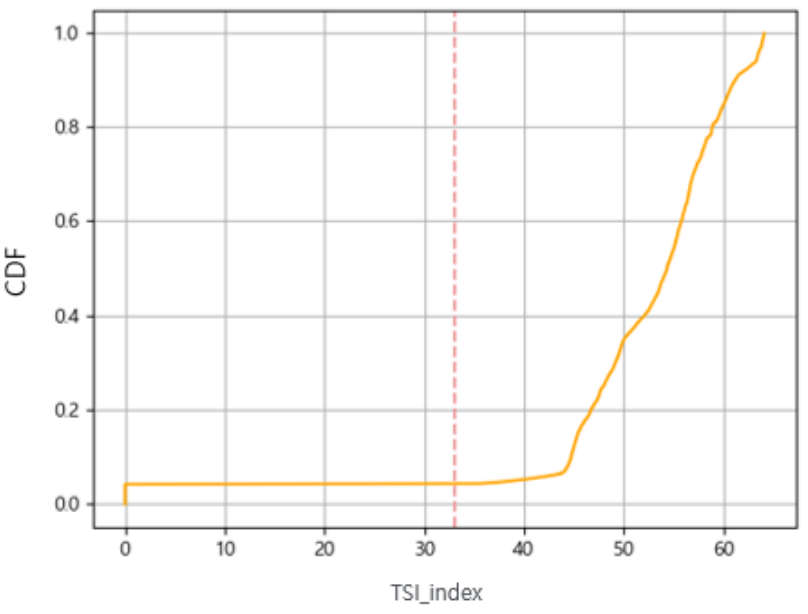

(b) Before reduction $\mathrm{CDF}$

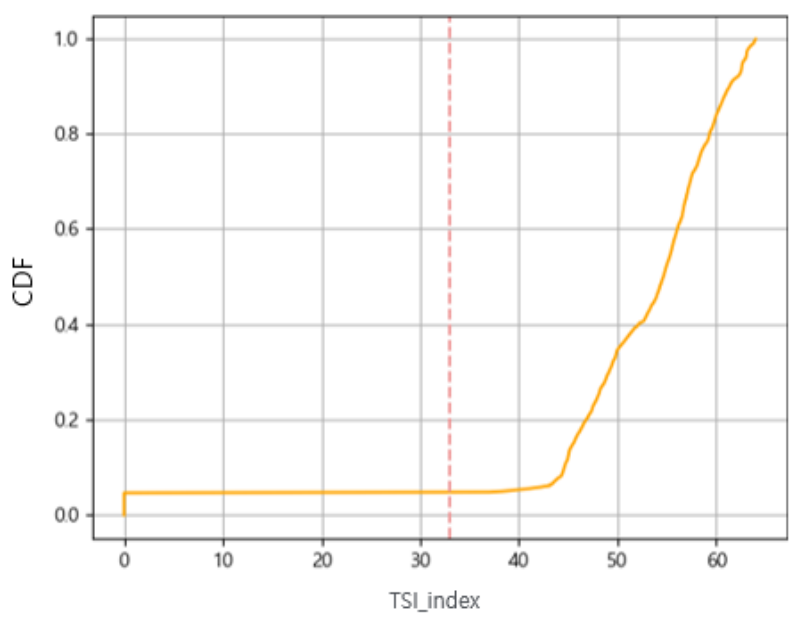

(d) After reduction CDF

Figure 14. $(\mathbf{a}, \mathbf{b})$ Before reduction PDF, CDF. (c,d) After reduction PDF, CDF. 


\subsection{Scenario $C$}

The transient stability assessment for the 95 cases in Scenario A takes a long time. Scenario $B$ reduced the time using system reduction, but still takes too long to simulate more cases. Therefore, in this scenario, the renewable energy capacity was calculated by estimating the TSI index with a few cases using the interpolation method. Contingency 1 was selected from the list of contingencies in Scenario A and B, as it has the highest risk and largest fluctuation in the TSI index. Out of the 95 cases, groups of $5 \%$ were selected and the effective capacity was calculated by estimating through interpolation using 13 TSI indices. As shown in Figure 15, it was calculated using an interpolation method from the 1st terms to the 6th terms. Based on this, the result of calculating the effective capacity of renewable energy at the East area was calculated as the $65 \%$ point. This is the result of the 6 th terms with the lowest error rate among each polynomial interpolation method. This showed an error of $2 \%$ from the simulation result of scenario A. Additionally, the simulation time was quite short, about $1 \mathrm{~min}$.

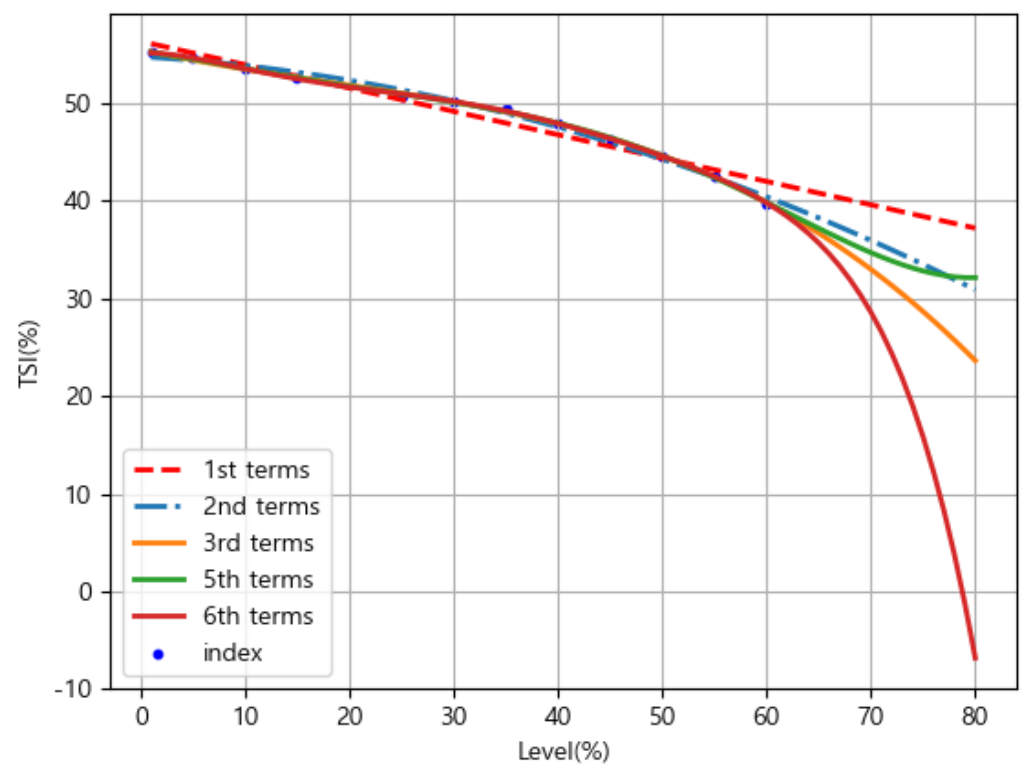

Figure 15. Interpolation-Based Transient Stability Assessment.

\subsection{Scenario D}

In this scenario, the gust model is used to increase the power production from renewable energy. For system interpretation, the scenario includes the followings: Only wind power is changed by the gust model. The capacity is determined by considering an increase by $100 \mathrm{MW}$ for every repetition.

- Including renewable energy of around 9.5 GW in the East area

- $\quad$ Load levels of $100 \%$

As shown in Table 6 below, two scenarios were reviewed. The renewable energy capacities in the regions without renewable energy and in Gangwon and Yeongdong regions were set with $3.5 \mathrm{GW}$ (PV), $5.4 \mathrm{GW}$ (wind), $700 \mathrm{MW}$ (others) to establish cases. Synchronous generators were reduced to adjust the supply and demand according to the renewable energy capacities added. In PSS/E, PV and wind powers were modelled as generators and other types of renewable energy were modelled as loads. In the renewable energy generator modelling, the control mode was basically in the power factor control mode, with PV at 1.0 and wind at 0.95 . Then, it was increased by $100 \mathrm{MW}$ for every simulation to determine the renewable capacity. 
Table 6. Result of Scenario E.

\begin{tabular}{cccc}
\hline & Scenario A & Scenario B & Scenario C \\
\hline Cases & 95 & 95 & 12 \\
Contingency list & 10 & 10 & 10 \\
Simulation time & $110 \mathrm{~min}$ & $77 \mathrm{~min}$ & $15 \mathrm{~min}$ \\
\hline
\end{tabular}

As shown in Figure 16, the probability that the TSI index falls below 35 is about $30 \%$. When the range of the TSI index is exceeded, the increase in renewable energy appears after increasing about $4.5 \mathrm{GW}$. This showed more acceptance than the previous scenario. This was judged as the difference between the amount of renewable energy in the uninterested area and the general generation each scenario.

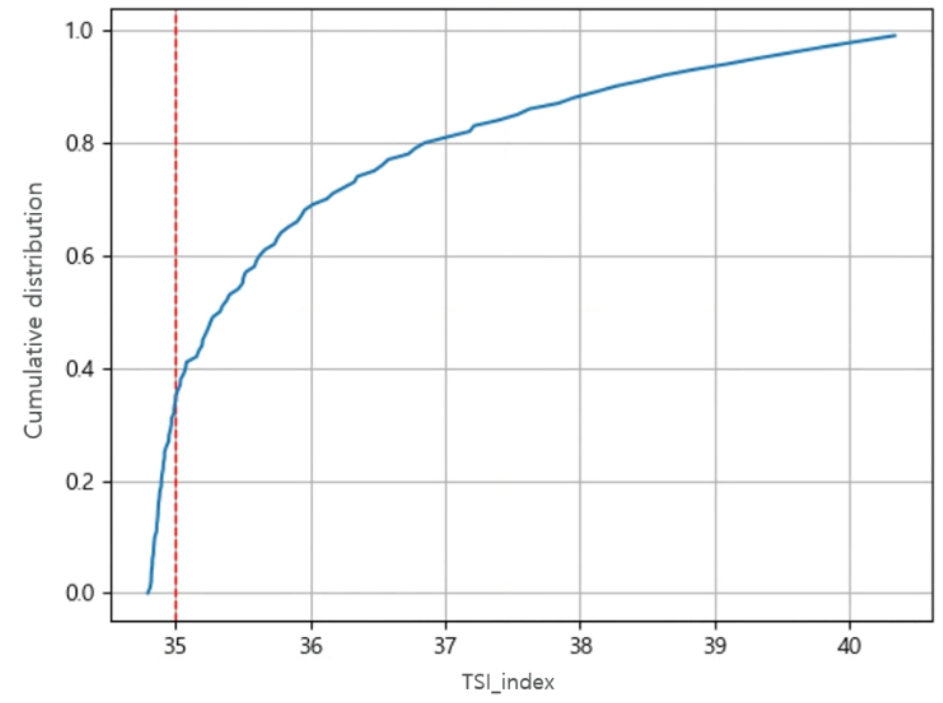

Figure 16. CDF of Scenario D.

\subsection{Scenario $E$}

This scenario aims to compare the operation time of scenarios A, B, and C. The simulation is performed under the same conditions and the calculation time is compared. The comparison conditions are as follows, and the total number of simulations is 950 . As for the CASEs selected for scenario C simulation, 120 selected cases were selected. The results are shown in Table 6. The computer used in this study has the specifications of CPU i9-10900 and RAM 32 GB.

- 95 Cases

- 10 Contingency list

\section{Simulation Result and Discussion}

The simulation was based on Python and PSS/E. We tested the receptivity of renewable energy in the East area of Korea through repeated simulations based on the Transient Stability Index (TSI). Prior to the simulation, a simple test determined that the TSI limit for Korea is 35 . For scenario A, accuracy was prioritized. As a result, the renewable capacity of Korea's East region increases rapidly in the system when about $63 \%(5.3 \mathrm{GW})$ of the effective capacity. The disadvantage of scenario $\mathrm{A}$ is that it takes a long time. In the case of scenario B, to secure this, the system was reduced except for the East area, which is an area of interest. In addition, the lines of less than $345 \mathrm{KV}$ in the uninterested area were abbreviated and the characteristics of the generator were maintained. This method significantly reduced the simulation time. There was a 3\% error in terms of accuracy. However, this is an acceptable error rate. Scenario $C$ used interpolation to predict acceptability limits by reviewing fewer scenarios. It used Python's Numpy internal function. The result was 
a significant reduction in time and a margin of error of $2 \%$. Scenario D, apart from the previous scenario, used the dynamic GAST model to perform a test with the variation of new regeneration. This affected the system by the rapid generators of the General Generators during the Dynamic Simulation. Thus, the results are quite stable. In the simulation conducted in this study, the transient stability was evaluated after constructing scenarios for the effective capacity. This has the disadvantage of taking the longest time apart from the static state. To solve this problem, we applied a technology that shortens the stability time through interpolation and system reduction. In practical terms, we think it is suitable to prepare for multiple scenarios when constructing a probabilistic scenario that predicts the generation of PV and wind generator.

\section{Conclusions}

Korea is striving to reduce thermal power generation and increase renewable energy to reduce carbon dioxide in line with renewable 3020 and international policies. In line with these policies, large-scale renewable energy complexes are rapidly increasing, especially solar and wind power. Renewable energy is characterized by high volatility and uncertainty. Many studies are underway to analyze system stability for these renewable energies. Among many studies recently, power system stability assessment for large-scale power system complexes has been conducted in deterministic method. Deterministic method can analyze properties of power systems through scenario creation, load flow calculation, and N-1 contingency analysis. However, when the volatility increases with alignment of a power system with renewable energy, this limits application of deterministic method. To supplement limitations of deterministic method, the probabilistic stability assessment method has been used, where scenarios extending to $8760 \mathrm{~h}$ are created to assess stability. Table 1 shows characteristics of the deterministic method and the probabilistic method to estimate renewable energy capacity limits. This paper introduces algorithms of the probabilistic transient stability assessment considering volatility and uncertainty of renewable energy. First, probabilistic scenarios were created based on the history of effective capacity and generation for $8760 \mathrm{~h}$ of renewable energy. A total of 8760 scenarios are created by applying the generation quantity from the historical data based on the input data of the maximum generation scenario. Second, a probabilistic transient stability assessment was conducted using transient stability index, interpolation-based transient stability index estimation, reduction-based transient stability index, etc. To reduce calculation time, which is a disadvantage of the probabilistic transient stability assessment, interpolation and reduction algorithms were applied to the transient stability assessment. Finally, a probabilistic transient stability assessment simulator was created based on the scenario creation, transient stability assessment algorithms, and probabilistic assessment. This paper created 5 scenarios to validate consistency of the proposed paper. The transient stability evaluation, which was previously conducted, tends to be limited in the selection of effective capacity. The probabilistic aspect presented in this paper prepares for the uncertainty of renewable energy. For this, many scenario are built over the steps mentioned above and the transient stability is evaluated based on various effective capacities. This can yield results for problems of power system that cannot be obtained in a deterministic evaluation. In future studies, renewable energy generation predictions are made based on past data and then a wide number of probabilistic scenarios are analyzed. We think this will be very helpful in making decisions in the mid- to long-term planning stage. For the analysis of such a wide range of scenarios, a multiprocessing process is used to improve accuracy while reducing simulation time as shown in Figure 17. 


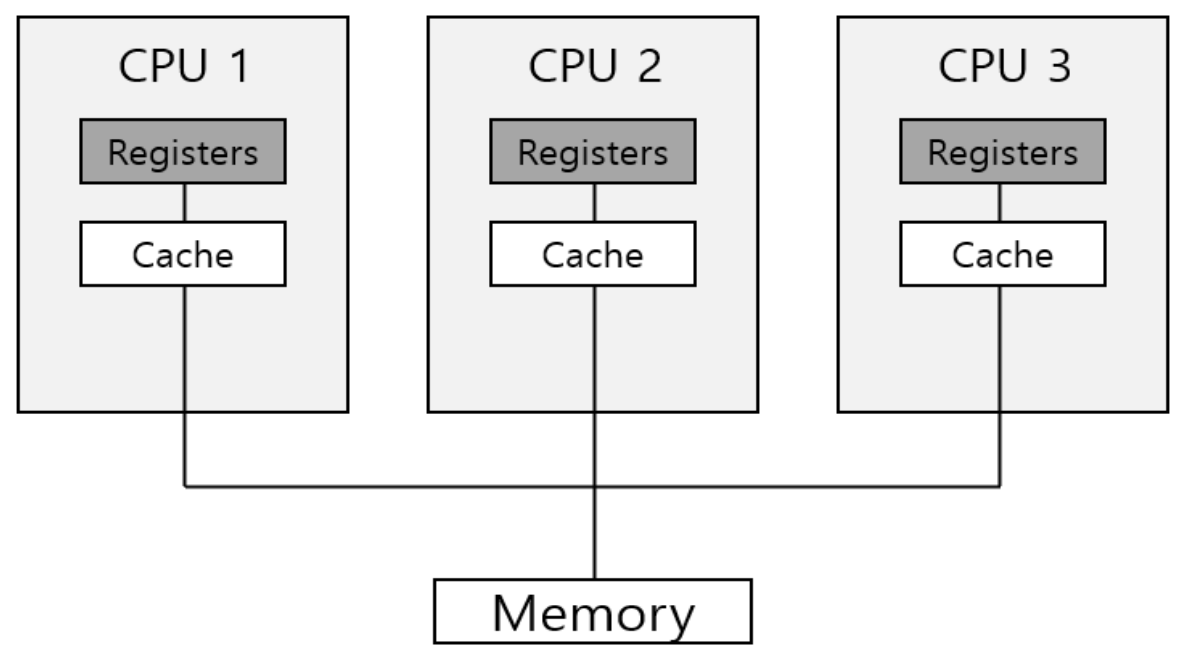

Figure 17. Multiprocessing Concept Drawing.

Author Contributions: Conceptualization, Y.-B.C. and Y.-S.C.; methodology, J.-G.L. and S.-C.O.; software, Y.-B.C. and Y.-S.C. validation, Y.-B.C. and Y.-S.C.; formal analysis, Y.-B.C. and Y.-S.C.; investigation, Y.-B.C., Y.-S.C., J.-G.L. and S.-C.O.; resources, Y.-B.C., Y.-S.C., J.-G.L. and S.-C.O.; data curation, Y.-B.C., Y.-S.C., J.-G.L. and S.-C.O.; writing-original draft preparation, Y.-B.C. and Y.-S.C.; writing-review and editing, Y.-B.C. and Y.-S.C.; visualization, Y.-B.C. and Y.-S.C.; supervision, Y.-S.C.; project administration, Y.-S.C.; funding acquisition, Y.-S.C., J.-G.L. and S.-C.O. All authors have read and agreed to the published version of the manuscript.

Funding: This work was supported by "Human Resources Program in Energy Technology" of the Korea Institute of Energy Technology Evaluation and Planning (KETEP), granted financial resource from the Ministry of Trade, Industry \& Energy, Republic of Korea. (No. 20194010201760). This work was supported by Korea Electric Power Corporation (KEPCO).

Institutional Review Board Statement: Not applicable.

Informed Consent Statement: Not applicable.

Data Availability Statement: Not applicable.

Conflicts of Interest: The authors declare no conflict of interest.

\section{References}

1. Ministry of Trade, Industry and Energy (MOTIE). The 8th Basic Plan of Long-Term Electricity Supply and Demand; Ministry of Trade, Industry and Energy (MOTIE): Sejong, Korea, 2017.

2. Ministry of Trade, Industry and Energy (MOTIE). Plan of Renewable Energy 3020 Implementation; Ministry of Trade, Industry and Energy (MOTIE): Sejong, Korea, 2017.

3. Jeju Island's New and Renewable Energy Power System Supplement 'Hourly Wage'. Available online: https://www.todayenergy. $\mathrm{kr} /$ news / articleView.html?idxno=232935 (accessed on 20 January 2021).

4. National Grid ESO (NGESO). Network Development Roadmap. Available online: https://www.nationalgrideso.com/researchpublications / etys-2020 / 4-year-round-probabilistic-analysis (accessed on 1 June 2018).

5. Tajdinian, M.; Allahbakhshi, M.; Seifi, A.R.; Chamorro, H.R.; Jahromi, M.Z.; Sood, V.K. An enhanced approach for probabilistic evaluation of transient stability. Int. J. Electr. Power Energy Syst. 2020, 120, 106055. [CrossRef]

6. Milanović, J.V. Probabilistic stability analysis: The way forward for stability analysis of sustainable power systems. Philos. Trans. R. Soc. A Math. Phys. Eng. Sci. 2017, 375. [CrossRef]

7. Kim, S.; Hur, J. Probabilistic Approaches to the Security Analysis of Smart Grid with High Wind Penetration: The Case of Jeju Island's Power Grids. Energies 2020, 13, 5785. [CrossRef]

8. Parajuli, A. A Statistical Analysis of Wind Speed and Power Density Based on Weibull and Rayleigh Models of Jumla, Nepal. Energy Power Eng. 2016, 8, 271-282. [CrossRef]

9. Carrillo, C.; Cidrás, J.; Díaz-Dorado, E.; Obando-Montaño, A.F. An Approach to Determine the Weibull Parameters for Wind Energy Analysis: The Case of Galicia (Spain). Energies 2014, 7, 2676-2700. [CrossRef]

10. Haupt, S.E.; Pestana, R.; Zack, J.; Casado, M.G.; Davidson, M.; Dobschinski, J.; Du, P.; Lange, M.; Miller, T.; Mohrlen, C.; et al. The Use of Probabilistic Forecasts: Applying Them in Theory and Practice. IEEE Power Energy Mag. 2019, 17, 46-57. [CrossRef] 
11. Ramírez, P.; Carta, J.A. Influence of the data sampling interval in the estimation of the parameters of the Weibull wind speed probability density distribution: A case study. Energy Convers. Manag. 2005, 46, 2419-2438. [CrossRef]

12. Alqunun, K.; Guesmi, T.; Albaker, A.; Alturki, M. Stochastic unit commitment problem, incorporating wind power and an energy storage system. Sustainability 2020, 12, 10100. [CrossRef]

13. Type 4-Generic Wind Turbine Generator Model (Phase II). Available online: https:/ / www.esig.energy/wiki-main-page/type-4generic-wind-turbine-generator-model-phase-ii / (accessed on 1 June 2015).

14. DSA Tools (Dynamic Security Assessment), TSAT User Manual; Powertech: Surrey, BC, Canada, April 2018; pp. 25-30.

15. Numpy Documentation. Available online: https://numpy.org/doc/stable/reference/generated/numpy.polyfit.html (accessed on 31 January 2021).

16. Siemns PTI. Documentation MODELS PSS/E 33 Manual; Siemns PTI: New York, NY, USA, 2013.

17. Siemns PTI. Documentation API PSS/E 33 Manual; Siemns PTI: New York, NY, USA, 2013. 